\title{
BMJ Open Descriptive, observational study of pharmaceutical and non-pharmaceutical arrests, use, and overdoses in Maine
}

\author{
Kevin J Simpson, ${ }^{1}$ Matthew T Moran, ${ }^{1}$ Michelle L Foster, ${ }^{2}$ Dipam T Shah, ${ }^{1}$ \\ Daniel Y Chung, ${ }^{1}$ Stephanie D Nichols, ${ }^{3}$ Kenneth L McCall, ${ }^{4}$ Brian J Piper ${ }^{1}$
}

To cite: Simpson KJ, Moran MT, Foster ML, et al. Descriptive, observational study of pharmaceutical and nonpharmaceutical arrests, use, and overdoses in Maine. BMJ Open 2019;9:e027117. doi:10.1136/ bmjopen-2018-027117

- Prepublication history and additional material for this paper are available online. To view these files, please visit the journal online (http://dx.doi. org/10.1136/bmjopen-2018027117).

KJS and MTM contributed equally.

Received 8 0ctober 2018 Revised 5 March 2019 Accepted 21 March 2019

Check for updates

(c) Author(s) (or their employer(s)) 2019. Re-use permitted under CC BY-NC. No commercial re-use. See rights and permissions. Published by BMJ.

${ }^{1}$ Medical Education, Geisinger Commonwealth School of Medicine, Scranton, Pennsylvania, USA

${ }^{2}$ Diversion Alert, Houlton, Maine, USA

${ }^{3}$ Pharmacy Practice, Husson University, Bangor, Maine, USA

${ }^{4}$ Pharmacy Practice, University of New England College of Pharmacy, Portland, Maine, USA

Correspondence to Dr Brian J Piper; bpiper@som.geisinger.edu; psy391@gmail.com

\section{ABSTRACT}

Objectives The Maine Diversion Alert Program grants healthcare providers access to law enforcement data on drug charges. The objectives of this report were to analyse variations in drug charges by demographics and examine recent trends in arrests, prescriptions of controlled substances and overdoses.

Design Observational.

Setting Arrests, controlled prescription medication distribution and overdoses in Maine.

Participants Drug arrestees $(n=1272)$ and decedents $(n=2432)$.

Primary outcome measures Arrestees were analysed by sex and age. Substances involved in arrests were reported by schedule (I-V or non-controlled prescription) and into opioids, stimulants or other classes. Controlled substances reported to the Drug Enforcement Administration (20072017) were evaluated. Drug-induced deaths (2007-2017) reported to the medical examiner were examined by the substance(s) identified.

Results Males were more commonly arrested for stimulants and schedule II substances. More than twothirds of arrests involved individuals under the age of 40 . Individuals age $\geq 60$ were elevated for oxycodone arrests. Over three-fifths (63.38\%) of arrests involved schedule IIIV substances. Opioids accounted for almost half (44.6\%) of arrests followed by stimulants (32.5\%) and sedatives (9.1\%). Arrests involving buprenorphine exceeded those for oxycodone, hydrocodone, methadone, tramadol and morphine, combined. Prescriptions for hydrocodone $(-56.0 \%)$ and oxycodone $(-46.9 \%)$ declined while buprenorphine increased ( $+58.1 \%$ ) between 2012 and 2017. Deaths from 2007 to 2017 tripled. Acetylfentanyl and furanylfentanyl were the most common fentanyl analogues identified.

Conclusions Although the overall profile of those arrested for drug crimes in 2017 involve males, age $<40$ and heroin, exceptions (oxycodone for older adults) were observed. Most prescription opioids are decreasing while deaths involving opioids continue to increase in Maine.

\section{INTRODUCTION}

Substance use disorders and overdoses are important health issues facing the USA. There were approximately 72000 overdose deaths in 2017 with two-thirds due to opioids. ${ }^{1}$ The Maine Diversion Alert Program (DAP)

\section{Strengths and limitations of this study}

- All arrests involving illicit or licit drugs reported to the Diversion Alert Program of Maine in 2017 were examined

- Controlled substance transactions reported to the Drug Enforcement Administration were evaluated.

- Drug-induced deaths $(n=2432)$ reported to the Maine Office of Medical Examiner were analysed.

- These complementary results from Maine may not generalise to larger states with younger or more diverse populations.

is an electronic resource available statewide since 2013 and was developed to combat drug diversion. ${ }^{2}$ Law enforcement agencies report information on individuals facing charges for drug-related crimes to a database shared with healthcare providers. ${ }^{23}$ This information is used to manage care plans so that further diversion of prescription drugs is limited. ${ }^{2}$ Arrestee demographics, $\operatorname{drug}(\mathrm{s})$ and offence(s) are relayed to the DAP to support prevention research and monitoring. ${ }^{24-6}$

Variations in drug use by sex and by age are of interest since women and the elderly have been overlooked. ${ }^{7-9}$ Drug misuse prevalence in the elderly may be underestimated due to addiction being mistaken for dementia, depression ${ }^{10}$ or so-called 'pseudoaddiction'. ${ }^{11}$ Female gender was a risk factor for substance use disorders among the elderly. ${ }^{12}$ A higher percentage of adult women in Maine received prescriptions for opioids, benzodiazepines and stimulants than did men. ${ }^{4}$ However, men in the USA generally report more illicit drug use of almost all varieties. ${ }^{9}$

Use of controlled substances is changing in the USA. ${ }^{4}{ }^{13}$ Relative to their peak in 2011, there were decreases by drug weight nationally in oxycodone $(-13.8 \%)$, morphine $(-18.9 \%)$, fentanyl $(-21.4 \%)$ and hydrocodone $(-28.4 \%)$ in $2016 .{ }^{5}$ A $25 \%$ production quota reduction of controlled 
substances by the Drug Enforcement Administration (DEA) in $2018^{14}$ may be anticipated to result in further decreases. Buprenorphine, used to treat an opioid use disorder (OUD), showed a pronounced elevation $(+75.2 \%) .{ }^{5}$ Although there are concerns about buprenorphine access, particularly in rural areas, 15 of the 16 Maine counties has at least one physician and one advanced-practice provider waivered to prescribe buprenorphine. $^{15}$

Overdoses are complex events that often involve multiple drugs of different classes (illicit, prescription, over the counter and alcohol) and pre-existing health vulnerabilities. Their incidence and reported origin should be interpreted with caution. ${ }^{16}{ }^{17}$ The US Centers for Disease Control and Prevention (CDC) recognises the varying quality of overdose determinations and classified states into three different categories: very good to excellent (25 states including Maine), good (7 states), and other (presumably less than good, 18 states). ${ }^{18}$ Testing practices depend on priorities and resources with variability across municipalities, especially for the more expensive confirmatory testing. ${ }^{19}$ Unfortunately, the drug implicated in over one-third of unintentional overdose deaths in five states was coded as 'unspecified'. 17

The epidemic of opioid overdoses has transitioned from prescription opioids to heroin to illicitly manufactured fentanyl. ${ }^{14}$ Although there are scores of known fentanyl analogues, WHO has paid particular attention to acetylfentanyl, butyrylfentanyl, acryloylfentanyl, carfentanil, furanylfentanyl and ocfentanil. ${ }^{20}$ Acetylfentanyl can be an artefact in the synthesis of illicit fentanyl. ${ }^{21}$
Carfentanil, an agent approved for veterinary use, has been identified in Ohio fatalities. ${ }^{22}$ The vast majority of illicit fentanyl and analogue deaths were male. ${ }^{20}$

The primary objective of this report was to provide an updated ${ }^{246}$ account of trends in drug charges as reported to the DAP and analyse variations in drug charges by sex and age. A secondary objective was to obtain information about how controlled substances and drug deaths have been changing over the last decade in Maine.

\section{METHODS \\ Subjects}

Law enforcement personnel submitted information regarding age, sex, town of residence, $\operatorname{drug}(\mathrm{s})$, offence, arrest date and reporting agency for persons with arrests / summons to the Maine DAP in 2017 who were age $\geq 18$ $(\mathrm{n}=1272, \quad 30.5 \%$ female, mean age $=33.69, \mathrm{SD}=9.68$, $\min =18, \max =67$ ).

The DEA's Automation of Reports and Consolidated Ordering System (ARCOS) monitors controlled substance transactions in the USA and territories. ARCOS is a comprehensive pharmacoepidemiology data source which tracks schedule II and III controlled substances provided to pharmacies, hospitals, emergency rooms, narcotic treatment programs (NTP), veterinarians and dentists at private and public (e.g., Veterans Affairs, Indian Health Services) facilities. ${ }^{5}$ Maine has a centralised state medical examiner system with the Office of the Chief Medical Examiner collecting information. ${ }^{1623}$ Maine received funding on 9/2016 for
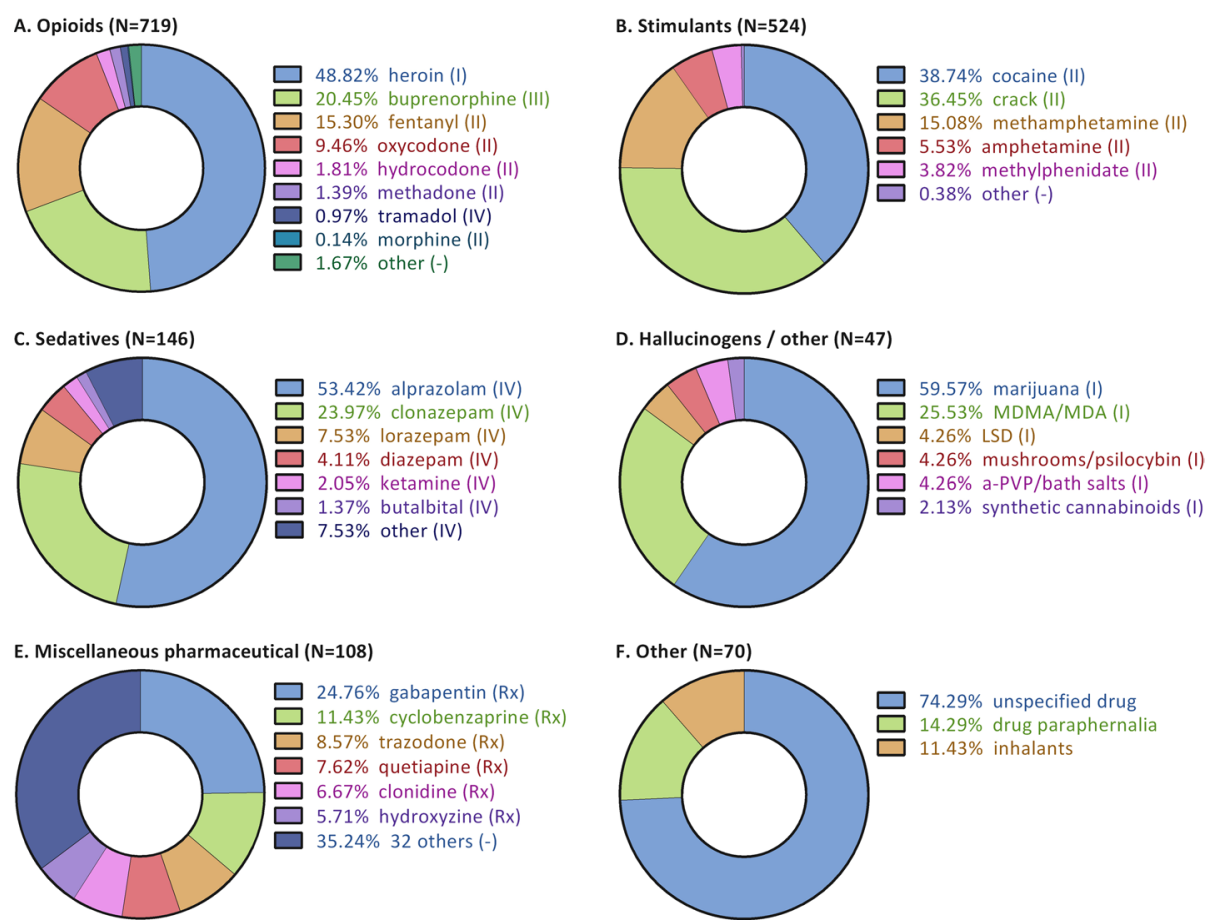

Figure 1 Drugs reported to the Maine Diversion Alert Program by class in 2017. The Federal Controlled Substances Act schedule is in parentheses. LSD, lysergic acid diethylamide; MDMA, methylenedioxymethamphetamine; MDA, methylenedioxyamphetamine; PVP, alpha-pyrrolidinopentiophenone. 
A.

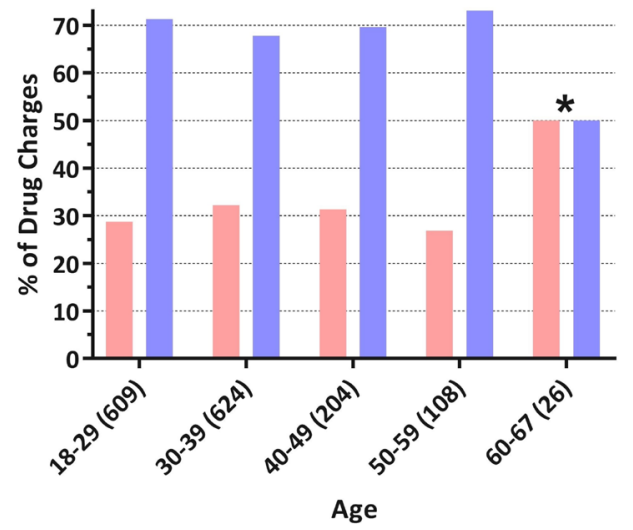

B.

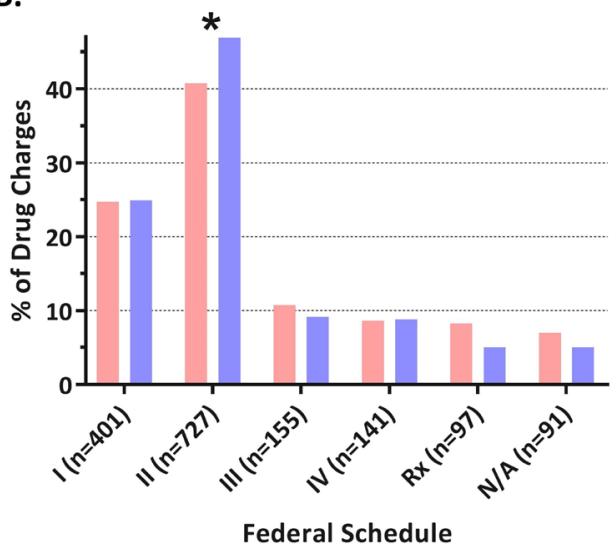

C.

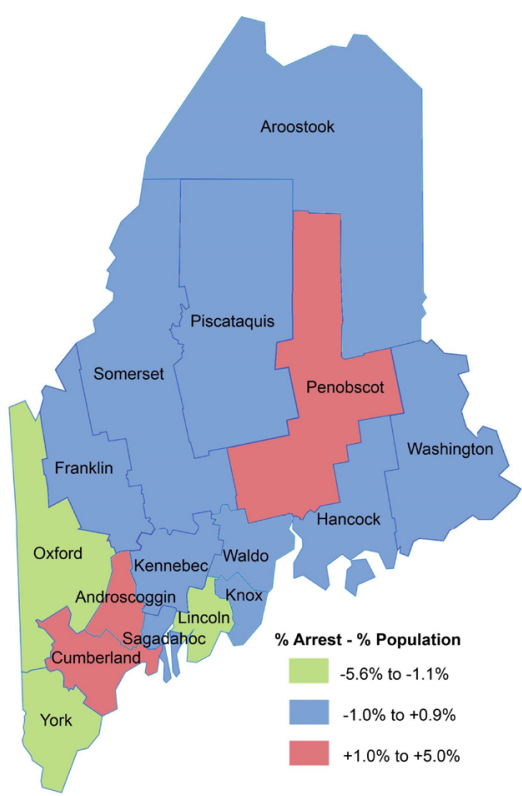

Figure 2 Sex and age (A), schedule and sex (B), and heat map (C) of drug charges reported to the Maine DAP in 2017. ${ }^{*} \chi^{2} p<0.05$ versus other ages (A) or versus other schedules (B).

the CDC Enhanced State Opioid Overdose Surveillance program.

\section{Procedures}

Drugs were categorised as schedule I (high potential for abuse, no accepted medical use) to $\mathrm{V}$ (lowest potential
Table 1 Drugs by class and sex reported to the Maine Diversion Alert Program in 2017

\begin{tabular}{llll} 
Class (N) & $\begin{array}{l}\text { Males } \\
(\mathbf{1 1 2 8}), \%\end{array}$ & $\begin{array}{l}\text { Females } \\
(\mathbf{4 8 6 )} \%\end{array}$ & $\begin{array}{l}\text { Female } \\
\text { ratio }\end{array}$ \\
\hline Opioids (719) & 69.26 & 30.74 & 2.25 \\
Stimulants (524) & 73.85 & 26.15 & $2.82 \dagger$ \\
$\begin{array}{l}\text { Sedatives (146) } \\
\begin{array}{l}\text { Misc pharmaceutical } \\
\text { (108) }\end{array}\end{array}$ & 69.18 & 30.82 & 2.24 \\
$\begin{array}{l}\text { Hallucinogens (47) } \\
\text { Other (70) }\end{array}$ & 68.09 & 39.81 & $1.51 \ddagger$ \\
\hline
\end{tabular}

${ }^{*} \chi^{2} p<0.05$ versus

tnon-stimulants or

łnon-miscellaneous pharmaceuticals.

for abuse, accepted medical use), prescription or other (eg, pseudoephedrine) in accordance to the US DEA Controlled Substance Act. Substances were classified into six families ${ }^{6}$ : opioids, stimulants, sedatives, hallucinogens, miscellaneous pharmaceutical or other (unspecified drug, drug paraphernalia, inhalants, figure 1).

ARCOS data ${ }^{5}$ were extracted as weight $(\mathrm{g})$ per agent in 2007, 2012 and 2017. Agents whose volumes were negligible $(<10 \mathrm{~g}$ in 2017$)$ were typically not reported. Overdose information (2007-2014) was obtained from the Maine Office of Attorney General. ${ }^{16} 2324$ The procedures employed in investigating drug deaths included a comprehensive toxicology screen and quantitative confirmatory testing (gas chromatography-mass spectroscopy) by National Medical Laboratories (Bakersfield). ${ }^{16} 2324$

\section{Data analysis}

Data were analysed with Epi Info, V.7.2.1.0. A $p<0.05$ was considered statistically significant although analyses that met more conservative thresholds were noted. $\chi^{2}$ analyses were completed for non-parametric measures (eg, sex) and t-tests for parametric measures (eg, drug weights). Heat maps were created with CARTO and QGIS, V.2.18.19. The term arrests was used interchangeably with drug charges which may also include summonses or indictments. The original spreadsheet was organised with a single row per offence. However, some offences $(20.0 \%)$ involved multiple drugs $(\max =7)$. The dataset was modified so that the unit of analysis was each unique drug arrest. ${ }^{2}{ }^{6}$ Agents were sometimes reported as 'unspecified drug', 'scheduled drug' or another similar variation. These agents were classified as 'other'. A regional analysis was conducted by calculating the difference between per cent arrests (\# arrests countywide/total arrests statewide) and per cent population (county population/state total population). ${ }^{4}$ Arresting agencies were classified as local: the department from each city/town; county; state: the Maine DEA and the Maine State Police or Federal: the Federal DEA, US Attorney's Office or Immigration and 
Table 2 Drugs by class and age reported to the Maine Diversion Alert Program database in 2017

\begin{tabular}{|c|c|c|c|c|c|c|}
\hline Age & $\begin{array}{l}\text { Opioids } \\
\text { (693), \% } \\
\end{array}$ & $\begin{array}{l}\text { Stimulants } \\
(508), \%\end{array}$ & $\begin{array}{l}\text { Sedatives } \\
(146), \%\end{array}$ & $\begin{array}{l}\text { Hal } \\
(46), \% \\
\end{array}$ & $\begin{array}{l}\text { MP } \\
(108), \% \\
\end{array}$ & $\begin{array}{l}\text { Other } \\
\text { (70), \% }\end{array}$ \\
\hline $18-29(609)$ & $37.8^{\star *}$ & $35.6^{*}$ & 10.5 & 3.5 & 8.2 & 4.4 \\
\hline $30-39$ (624) & $50.6^{\star \star}$ & 30.0 & 8.5 & 2.1 & 5.0 & 3.9 \\
\hline $40-49$ (204) & 45.6 & 27.5 & 8.8 & 3.9 & 8.3 & 5.9 \\
\hline $50-59(108)$ & 38.9 & 39.8 & 9.3 & 1.9 & 8.3 & 1.9 \\
\hline$>60(26)$ & 46.2 & 19.2 & 3.9 & 7.7 & 3.9 & $19.2^{*}$ \\
\hline
\end{tabular}

$\mathrm{N}$ is in parentheses.

$* 2 \times 2 \chi^{2} p<0.05$.

${ }^{\star *} \mathrm{P}<0.001$ versus other ages or drug classes.

MP, miscellaneous pharmaceutical; Hal, hallucinogens.

Customs Enforcement. County and state populations were derived from the US Census Bureau's 1 April 2017 population estimates. Drug weights from ARCOS were expressed relative to 2007 and 2012 with a $\pm 5 \%-19 \%$, $20 \%-39 \%$ and $\geq 40 \%$ change interpreted as small, moderate and large, respectively. A 2 (year) x 2 (illicit positive versus negative) $\chi^{2}$ tested whether the observed frequencies of drug fatalities differed relative to 2007 .

\section{RESULTS}

Drug arrests

There were 1272 arrests reported. Multiple drug arrests per arrestee were separated resulting in 1614 unique drug charges. Drug offences reported to the DAP included possession $(53.90 \%)$, trafficking $(21.87 \%)$, distribution $(8.92 \%)$, possession with intent to distribute $(5.64 \%)$, operating under the influence $(2.42 \%)$, manufacturing $(1.12 \%)$ and other $(6.13 \%)$. Local agencies accounted for over half of the drug arrests $(53.47 \%)$, followed by state $(24.97 \%)$, federal $(13.88 \%)$ and county $(7.68 \%)$ agencies.

Figure 1 shows arrest data by class including opioids ( $44.55 \%$ of arrests), stimulants (32.47\%), sedatives $(9.06 \%)$, miscellaneous pharmaceutical (6.69\%), hallucinogens $(2.91 \%)$ and others $(4.34 \%)$. Figure 1A illustrates how heroin, buprenorphine and fentanyl were responsible for the preponderance $(84.57 \%)$ of opioid arrests. Cocaine/ crack cocaine and methamphetamine accounted for most $(90.27 \%)$ stimulant arrests (figure 1B). Over half of sedative arrests were for alprazolam (figure 1C) and three-fifths of hallucinogen arrests were for marijuana (figure 1D). The miscellaneous pharmaceutical included many (38) diverse non-controlled prescription agents of which gabapentin, cyclobenzaprine, trazodone and quetiapine constituted the majority $(50.92 \%$, figure $1 \mathrm{E})$. Three-quarters of the other arrests involved substances whose identity was unknown at the time of arrest.

Males accounted for over two-thirds of arrests $(69.50 \%)$. The average age for males was 33.44 $(\mathrm{SD}=9.68, \min =18, \max =67)$, and the average age of females was $34.23(\mathrm{n}=386, \mathrm{SD}=9.65, \min =19, \max =67)$. Arrestees $(\mathrm{n}=1246)$ were grouped by age: 18-29 (37.73\% of arrests), 30-39 (38.66\%), 40-49 (12.64\%),
50-59 (6.69\%) and 60-67 (1.61\%). Figure 2A compares arrests by sex and age. Males accounted for two-thirds of each age group which was significantly different from older adults $(\geq 60)$. Table 1 compares male and female arrests by drug category. Relative to the overall pattern of 2.32 male arrestee relative to each female, there were an increased number of males for stimulant arrests and more females for non-controlled pharmaceuticals. The sex ratio differed between stimulants and opioids $\left(\chi^{2}(1)=3.75, p \leq 0.053\right)$.

One-quarter $(24.85 \%)$ of arrests involved a schedule I drug, $45.04 \%$ schedule II, $9.60 \%$ schedule III, $8.74 \%$ schedule IV, $0.21 \%$ schedule V, $6.01 \%$ prescription (non-controlled) and $5.64 \%$ non-prescription. Figure 2B compares arrests by federal drug classification in males and females. Males were significantly more $(p<0.001)$ likely arrested for schedule II drugs than females.

Table 2 shows data for arrests of each age group per drug category. Among arrestees ages 18-29, opioids were more common $(\mathrm{p}<0.001)$ and stimulants were less common $(\mathrm{p}<0.03)$. Among those arrested in ages $30-39$, arrests for opioids were elevated $(\mathrm{p}<0.001)$. Arrestees $>60$ and older were arrested significantly more than those younger for other substances. For those under 40 , the percentage of heroin arrests $(23.11 \%)$ was almost double that for those $50+(11.94 \%) \quad(\mathrm{p}<0.002)$. Conversely, the proportion of arrests for oxycodone for those $50+(13.43 \%)$ was fivefold higher than that for those under $40(2.68 \%) \quad(\mathrm{p}<0.001)$.

Figure 2C shows arrests per county corrected for population. York $(-5.6 \%)$, Lincoln $(-1.6 \%)$ and Franklin $(-1.3 \%)$ had the lowest and Androscoggin (+2.3\%), Cumberland $(+4.7 \%)$ and Penobscot $(+5.0 \%)$ had the highest arrests.

\section{Prescription drug use}

Table 3 shows that although Maine population was stable over the last decade, use of controlled substances has undergone dynamic changes. In 2012, there were large increases in oxymorphone, buprenorphine, hydromorphone, lisdexamfetamine and amphetamine but large decreases in meperidine and cocaine relative to 2007. In 
Table 3 Controlled substances ( $\mathrm{g}$ ) in Maine as reported to the Drug Enforcement Administration's Automation of Reports and Consolidated Ordering System

\begin{tabular}{|c|c|c|c|}
\hline & $\underline{2007}$ & $2012(\%$ of 2007$)$ & 2017 (\% of 2012) \\
\hline \multicolumn{4}{|l|}{ Opioids } \\
\hline Oxycodone (II) ${ }^{1.5}$ & 309762 & $384475(+24.1)$ & $204308(-46.8)$ \\
\hline Methadone $(\mathrm{II})^{10}$ & 164090 & $167642(+2.2)$ & $126225(-24.7)$ \\
\hline Morphine (II) ${ }^{1}$ & 119823 & $117676(-1.8)$ & $65934(-44.0)$ \\
\hline Hydrocodone (II) $)^{1}$ & 113910 & $155652(+36.6)$ & $68460(-56.0)$ \\
\hline Codeine (II) ${ }^{1}$ & 72375 & $63062(-12.9)$ & $41556(-34.1)$ \\
\hline Buprenorphine (III) ${ }^{10}$ & 11343 & $24481(+115.8)$ & $38720(+58.1)$ \\
\hline Meperidine (II) 0.1 & 9888 & $5506(-44.3)$ & $1578(-71.3)$ \\
\hline Hydromorphone (II) ${ }^{4}$ & 5196 & $7946(+52.9)$ & $6686(-15.8)$ \\
\hline Fentanyl base $(\mathrm{II})^{75}$ & 2053 & $2612(+27.2)$ & $1323(-49.4)$ \\
\hline Oxymorphone (II) ${ }^{3}$ & 1101 & $4781(+334.4)$ & $3699(-22.6)$ \\
\hline Opium powdered (II) ${ }^{1}$ & 184 & $211(+14.5)$ & $199(-5.6)$ \\
\hline Tapentadol (II) ${ }^{0.4}$ & NA & 112412 (NA) & $5636(-49.9)$ \\
\hline \multicolumn{4}{|l|}{ Stimulants } \\
\hline Methylphenidate (II) & 125473 & $157025(+25.1)$ & $141225(-10.1)$ \\
\hline Amphetamine (II) & 49039 & $69807(+42.4)$ & $90672(+29.9)$ \\
\hline Lisdexamfetamine (II) & 2469 & $57836(+22420.1)$ & $67311(+16.4)$ \\
\hline Cocaine (II) & 271 & $147(-46.0)$ & $87(-40.3)$ \\
\hline \multicolumn{4}{|l|}{ Barbiturates } \\
\hline Pentobarbital (II) & 83213 & $69998(-15.9)$ & $80881(+15.5)$ \\
\hline Butalbital (III) & 8435 & $7590(-10.0)$ & $2520(-66.8)$ \\
\hline Population (millions) & 1.327 & $1.328(+0.1)$ & $1.336(+0.7)$ \\
\hline
\end{tabular}

US Controlled Substance Act schedule is in parentheses; Morphine mg equivalent of opioids is in superscripts. Maine population is from the US Census.

NA, not applicable (approved in 2008).

2017, large increases were observed for buprenorphine, amphetamine and lisdexamfetamine but large decreases for meperidine, butalbital, hydrocodone, tapentadol, oxycodone, morphine and cocaine relative to 2012. Moderate declines were found for codeine, methadone and oxymorphone while amphetamine exhibited a moderate increase.

Further analyses were completed on the opioid with the largest increase (buprenorphine) and one of the larger decreases (hydrocodone). Online supplementary figure 1A shows a heat map by three-digit zip code depicting the over 30-fold (31.6) differences in the elevations in buprenorphine. Online supplementary figure $1 \mathrm{~B}$ depicts a more homogeneous reduction in hydrocodone with a threefold (3.38) difference between zip codes.

\section{Drug-related mortality}

The number of drug deaths increased 2.7-fold from 2007 (154) to 2017 (418) with $>10 \%$ elevations, relative to the preceding year, from 2014 to 2017 (figure 3A). The percentage of decedents for whom an illicit drug was listed as a cause of death on the death certificate that tested positive for illicit drugs, was significantly lower than 2007 (31.8\%) in 2008 to 2011 (11.4\% to 18.3\%) but higher from 2014 to 2017 (43.8\% to $80.8 \%$ ).

In 2017 , almost three-quarters $(71.5 \%)$ of decedents were male (2.51 males: 1 female) with an average age of $41(\min =18$, maximum $=94)$. The vast majority $(87.3 \%)$ of drug deaths were accidents, with suicides accounting for one out of nine $(11.7 \%)$, and the remaining undetermined $(1.0 \%)$. Figure 3B depicts drug deaths in 2017 during which three-quarters or more were caused by two or more drugs, typically three, and an opioid, either pharmaceutical or illicit. Three-fifths were caused by a pharmaceutical drug and an equivalent amount included illicit fentanyl or a fentanyl analogue. Benzodiazepines, cocaine or heroin/morphine were each identified in one-fifth of cases. Figure 3C shows the top seven fentanyl analogues identified with acetylfentanyl in less than half and furanylfentanyl in over one-quarter. Pharmaceutical opioids included oxycodone $(12.7 \%$ of all decedents), methadone $(7.4 \%)$ and buprenorphine $(5.3 \%)$. Non-pharmaceutical fentanyl was 80 -fold more common than pharmaceutical fentanyl (247 vs 3). 

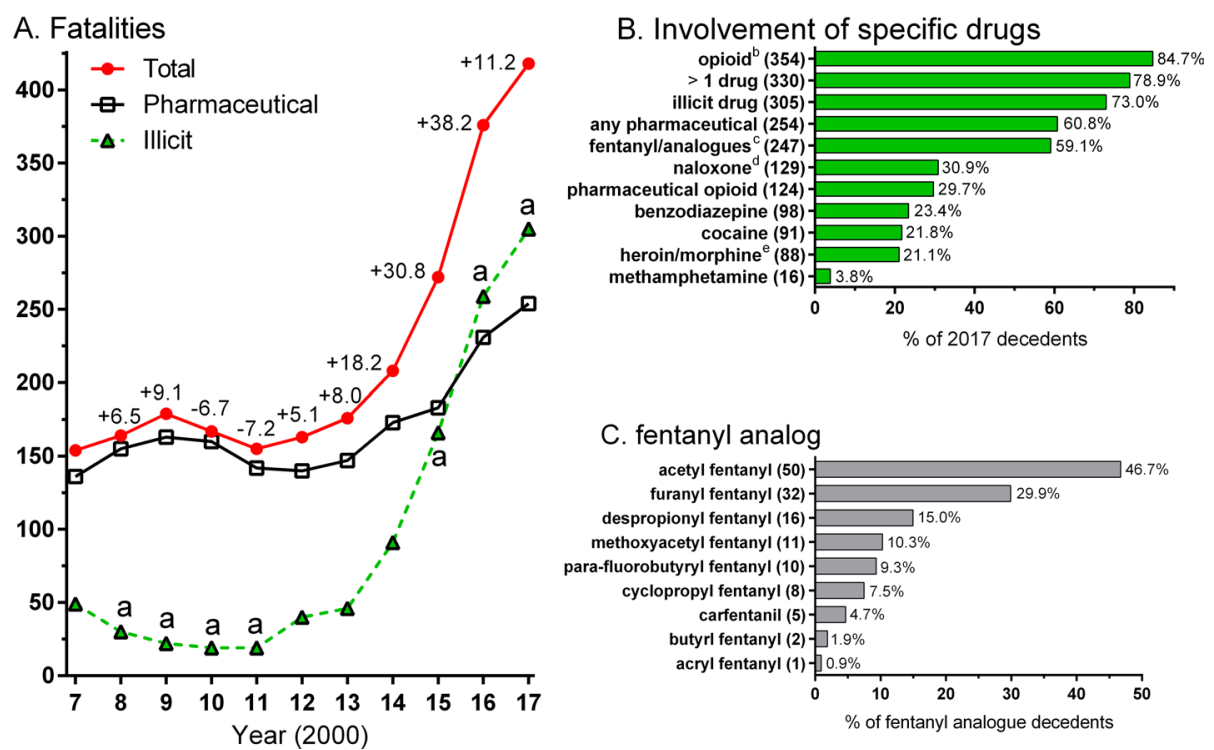

Figure 3 Fatalities due to drugs in Maine from 2007 to 2017 (A). Illicit drug includes heroin/morphine, non-pharmaceutical fentanyl, fentanyl analogues, cocaine, methamphetamine, U-47700, mitragynine and methylenedioxymethamphetamine. Per cent change relative to prior year is shown above the total. ${ }^{a} \chi^{2} p \leq 0.005$ for number of fatalities involving illicit drugs versus 2007. Involvement of specific drugs among fatalities in 2017 ( $n=418$ ), (B). ${ }^{b}$ Pharmaceutical and non-pharmaceutical, ${ }^{c}$ excludes pharmaceutical fentanyl, ${ }^{d}$ excludes buprenorphine cases, ${ }^{e}$ excludes pharmaceutical morphine. Involvement of specific fentanyl analogue in 2017 ( $n=107)$, (C).

\section{Patient and public involvement}

Arrestees and patients were not involved in this research.

\section{DISCUSSION}

Drug diversion, misuse and overdoses continue to be pressing public health issues. ${ }^{18}$ The first objective of this investigation was to provide updated information from the Maine DAP. The DAP is an informational resource to improve healthcare decision-making and prevent substance use disorders. This report contains data from 2017 and extends on prior DAP reports from $2014,{ }^{4} 2015^{2}$ and $2016^{6}$; controlled substance investigations ${ }^{4513}$ and drug-related mortality reports. ${ }^{162324}$ The first objective was to identify the substances involved in crime. Heroin arrests were highest in Maine in 2017. DEA arrest data showed that yearly heroin arrests almost doubled from 2007 to $2014 .{ }^{16}$ Many heroin users, particularly the younger ones, were previously prescription opioid users. ${ }^{25} 26$

The second objective was to determine how overdoses are changing. Fentanyl's importance in medical management of pain is high due to its rapid onset of action and varied routes of administration, including intravenous, transdermal and transmucosal formulations. ${ }^{27}$ Fentanyl also has a high risk for nonmedical use as it can be synthetised by modifying meperidine. Fentanyl is illegally sold as a powder or mixed with heroin or cocaine and can be sold unknowingly to heroin or cocaine buyers at a lower cost. ${ }^{28}$ Since it is much more potent than heroin, it is easier to transport smaller quantities of fentanyl across borders. Additionally, the high potency of fentanyl and the unpredictable dose cutting has been shown to lead to a high number of overdoses. ${ }^{18}$ Sporadic epidemics of fentanyl derivatives have been occurring over four decades. ${ }^{19}$ Laboratory testing showed a substantial drop from 2010 to 2016 in stamp bags from Allegheny county Pennsylvania containing only heroin. ${ }^{29}$ Illicit fentanyl and analogues were responsible for an increasing proportion of drug-related deaths in Maine. Among the analogues, acetylfentanyl was most frequent followed by furanyl, despropionyl, and methoxyacetyl fentanyl. Carfentanil, unlike in Ohio, ${ }^{22}$ was uncommon.

Buprenorphine is a partial mu agonist and kappa receptor antagonist that is used to treat OUD, reduces mortality and overdose, and increases quality of life. ${ }^{30}$ As buprenorphine arrests exceeded those for oxycodone, hydrocodone, methadone, tramadol and morphine, combined, further monitoring is needed. Those arrested for buprenorphine, typically for possession, may be self-medicating for an OUD, or may be otherwise using the medication for non-medical purposes. With parenteral self-administration, buprenorphine can produce similar effects to full mu agonists. ${ }^{31}$ It is imperative that buprenorphine prescribers are engaging OUD patients in other pharmacological and non-pharmacological treatments ${ }^{32}$ to reduce the risk of relapse and buprenorphine diversion.

Access to OUD treatments outside of NTP has been a persistent concern. National legislation has increased the number of OUD patients that can receive buprenorphine from physicians, physician assistants and nurse practitioners. ${ }^{15}$ Mid-coast Knox County was the only one in Maine lacking an advanced-practice provider waivered for buprenorphine in 2017. ${ }^{15}$ Although all zip codes showed increases in prescribed buprenorphine, mid-coastal areas showed the largest elevations. States that have expanded 
Medicaid had $70 \%$ elevations in Medicaid covered prescriptions. ${ }^{33}$ Maine has not expanded Medicaid during the time frame of this study.

Men were arrested more than women for almost all drugs. This is also true nationally where men report more illicit drug use of almost all varieties ${ }^{9}$ and fentanyl analogue overdoses. ${ }^{20}$ While the national ratio of adult men to women with drug abuse violations is $3.8: 1,{ }^{34}$ this difference is smaller in Maine (2.3:1). However, this arrest ratio is inconsistent with prescription trends. A higher percentage of adult women received prescription opioids, benzodiazepines and stimulants than men $^{4}$, all drug classes for which more men are entered into the Maine DAP for violations related to non-medical use. Women are more likely to have chronic pain, ${ }^{35}$ and thus, they may require more analgesic prescriptions. Heightened benzodiazepine prescriptions may be because women are more at risk for anxiety disorders ${ }^{36}$ and insomnia. ${ }^{37}$ That women receive more prescriptions for these potentially misuse drugs and that women are just as likely to become addicted to substances as men ${ }^{38}$ begs the question as to why women are not arrested for substances as frequently as men.

The percentage of charges for schedule II drugs among men was higher than for women. This corresponds with the disproportionately high proportion of men who were charged for stimulants as many stimulants are schedule II. Despite this difference, women were shown to develop a dependence to cocaine at a similar rate as men. ${ }^{38}$ Women may show both a higher dependence on methamphetamine than men as well as an earlier age of first usage. ${ }^{39}$ Additionally, gender does not appear to bias the approval rating of non-medical use of stimulants among college students. ${ }^{40}$ However, women generally use cocaine for shorter periods of time ${ }^{30}$ and may respond more favourably to methamphetamine dependence treatment. ${ }^{39}$ These factors may help to explain the disproportionately high number of men arrested for stimulants.

For most age groups analysed, men make up more than two-thirds of DAP arrests. However, for individuals in their 60s, women accounted for half of DAP arrests. This corresponds to national data that the prevalence of women with substance use disorders among the elderly is disproportionately high. ${ }^{11}$ The proportion of DAP entries for oxycodone increased as age increased such that it was more than fivefold higher among those $\geq 50$ than it was among those under 40 . Correspondingly, the proportion of DAP entries for heroin charges decreased with age such that heroin arrests among those under 40 was about twice as high as that for individuals $>50$. A possible explanation is that oxycodone tends to be a prescription drug, unlike heroin. Opioid prescriptions and chronic opioid prescriptions, in particular, are less common among younger individuals but are more common for individuals over the age of forty and peak for patients in their ninth decade. ${ }^{4}$ These data suggest that older individuals may have easier ongoing access to oxycodone than younger- adults who turn more to non-prescription opioids such as heroin, particularly if prescription opioids become unavailable after the development of dependency.

The highest amount of drug arrests, when corrected for population, were in Penobscot and Cumberland counties which is congruent with earlier reports. ${ }^{246}$ Penobscot county is the location of Bangor, the third most populated city in Maine, and Cumberland county is the location of Portland, the most populated city. The zip code including Bangor had pronounced ( $>50 \%$ ) declines in hydrocodone prescriptions (figure 3B). Interestingly, York county, second for population, had the lowest amount of drug arrests per population density. Accounting for its location on the border of New Hampshire and being a popular tourist location, we hypothesise that this difference is due to the fluidity of the population in the county throughout the year.

A non-negligible $(>100)$ number of arrests involved non-controlled prescription substances (figure $1 \mathrm{~F}$ ) which has been noted previously. ${ }^{2}{ }^{6}$ These arrestees tend to be more likely to also be charged with offences involving more other drugs and to be slightly older. ${ }^{6}$ There are several possibilities to account for the presence of these drugs in arrest records. First, the agents identified are among the bestselling agents in drugs (sertraline, trazodone, quetiapine, gabapentin, cyclobenzaprine and pregabalin). It is very possible that these drugs were obtained without permission from others or were being misused based on a limited understanding of their pharmacology. Second, currently known cutting agents (caffeine, hydroxyzine, lidocaine), ${ }^{41}{ }^{42}$ were only sporadically identified. Third, some drugs (eg, cyclobenzaprine, quetiapine) have sufficient antimuscarinic or antihistamine binding that, likely when used at higher than recommended doses, can produce subjective states (stimulant, mildly euphoric, sedative or hallucinogenic) that some users experience positively. ${ }^{2}$ Some people who inject drugs have discovered that the antipsychotic promethazine can be combined with buprenorphine and a benzodiazepine (ie, the South Asian cocktail) to self-medicate for symptoms of depression or anxiety. ${ }^{43}$ Fourth, gabapentin, pregabalin and tricyclic antidepressants are treatment options for postherpetic neuralgia. ${ }^{44}$ A population with criminal justice involvement is at heightened risk for sexually transmitted infections. A subset of arrestees may be attempting to self-medicate for different types of pain or drug withdrawal. Finally, the potential of some of these agents to be misused and abused may be much greater than their non-controlled status implies. ${ }^{45}$ Opioid misusing populations are at elevated risk for gabapentin abuse. ${ }^{47}$ Bupropion is a member of the cathinone family and exceeding the recommended dosing or non-oral routes of administration may heighten the dopaminergic and euphoric effects. ${ }^{48}$ Collectively, ${ }^{26}$ there could be benefits to tracking all prescription medications. ${ }^{14}$

The presence of naloxone in almost one-third of drug-related deaths is concerning. However, this finding should be viewed within the context of the high, and increasing prevalence of naloxone use. ${ }^{49} 50$ The ability of naloxone to act as a reversal agent is dependent on the timing of administration and the agonist's potency. Relative to morphine, 
parafluorofentanyl, acetylfentanyl, fentanyl, $\alpha$-methylfentanyl and carfentanil are $9,{ }^{51} 16,{ }^{51} 54,,^{51} 57^{51}$ and $10000^{52}$ times more potent. Not all pharmacies ${ }^{53}$ in this rural state are making naloxone nasal spray available for adults as they are legally permitted to do.

Three caveats with these data sources are noteworthy. One limitation is that the DAP data reflect drug charges. Illicit use of recreational or medical drugs may differ from that which is identified by the criminal justice system. This difference may be due to some drug user's abilities to avoid arrest or by law enforcement priorities, judgement and discretion. The DAP received arrest data until 31 March 2018 and is no longer in operation (online supplementary data). Data reported to the DAP in 2015 and 2016 were similar in number (almost three thousand), while only sixteen hundred charges were reported in 2017. Reduced arrests recently could be indicative of diminished reporting. Pharmacoepidemiological reports of controlled substances often employ data sources that exclude important segments of the US population (NTP recipients, veterans, Indian Health Services). The DEA's ARCOS is the most comprehensive data source available. ${ }^{5}$ However, ARCOS does not track controlled substances that may enter Maine from mailorder pharmacies or the dark web. The overdose reporting system is not homogeneous across states including the qualifications of members of the death investigation teams and use of confirmatory testing. Although Maine's reporting is rated as top-tier, ${ }^{17}{ }^{18}$ intrastate (ie, longitudinal) comparisons should be made with the recognition that death determination resources (eg, the ability to send medical examiner staff to the scene when someone dies outside of the hospital $)^{24}$ are finite. Finally, Maine has limited diversity and an older population which may limit generalisability to states with different demographics.

There may be some considerations with the DAP relative to the more long-standing Prescription Drug Monitoring Programs (PDMP) ${ }^{54}$ which may be beneficial to others considering developing novel prevention programs. PDMPs provide invaluable information for law enforcement, particularly in the event of overdoses. A barrier to PDMPs being more impactful (eg, decreasing overdoses) is these have been appreciably underused. ${ }^{55}$ Over fourfifths of licensed osteopathic physicians, dentists and pharmacists, and two-thirds of allopathic physicians had not registered with the DAP. ${ }^{6}$ The DAP did not obtain information about arrestee ethnicity which unfortunately precluded examination of this variable. Future DAP implementations could integrate with the PDMP and electronic medical records to improve ease of use. Substantial healthcare provider education and outreach are also important. PDMPs required some investment with start-up costs from US $\$ 450 \mathrm{~K}-1.5$ million and annual operating costs from US $\$ 125000$ to US $\$ 1$ million. ${ }^{56}$ The DAP was operated with three part-time employees (further information on the DAP budget, operation and improvements are in the online supplementary appendix). In comparison, dependence, abuse and overdose of just prescription opioids were estimated to cost US\$78.5 billion ${ }^{57}$ or US $\$ 330$ million in Maine.

In conclusion, the Maine DAP worked to promote communication between law enforcement and healthcare providers to limit drug diversion and facilitate treatment. Drug arrests are important information which complements other pharmacoepidemiological indices like drug seizures, pharmaceutical use, emergency medical services and overdoses. Our hope is that this report will inform healthcare providers, epidemiologists and policy-makers of the current status of the opioid crisis in New England. Identification of high-risk populations in future programmes implemented elsewhere will further combat substance use disorder and drug-related morbidity and mortality.

Acknowledgements Thanks to Iris Johnson and Carmella DeBiasi for technical assistance. Marci Sorg provided insightful feedback on an earlier version of this manuscript and John Herbert provided detailed Diversion Alert Program administrative information.

Contributors KJS and MTM performed the data analysis, prepared figures and wrote the first manuscript versions. KJS, MTM, MLF and DYC performed data collection. DTS and DYC provided technical assistance. KJS, MTM, SDN, KLM and BJP were responsible for study design. All authors approved the final version.

Funding This publication was supported by Fahs-Beck Bund for Research and Experimentation.

Disclaimer Its contents are solely the responsibility of the authors and do not necessarily represent the official views of our affiliated institutions.

Funders had no role in the research or dissemination process.

The depiction of boundaries on the map(s) in this article do not imply the expression of any opinion whatsoever on the part of BMJ (or any member of its group) concerning the legal status of any country, territory, jurisdiction or area or of its authorities.

The map(s) are provided without any warranty of any kind, either express or implied.

Competing interests This research and KJS, MTM and SDN were supported by the Fahs-Beck Fund for Research and Experimentation, a non-profit organisation. MLF was an employee of Diversion Alert. BJP has received research support and travel related to medical marijuana. The other authors have no relevant disclosures.

Patient consent for publication Not required.

Ethics approval The Wright Center IRB approved the DAP procedures (GCSOM03232017BP) and the UNE IRB approved ARCOS and overdose procedures (\#20180410-009).

Provenance and peer review Not commissioned; externally peer reviewed.

Data sharing statement Prescription data are publicly available at: https:// www.deadiversion.usdoj.gov/arcos/retail_drug_summary/index.html. Overdose information is available at: https://mcspolicycenter.umaine.edu/wp-content/ uploads/sites/122/2018/04/Final-Annual-2017-Drug-Death-Report_.pdf. Our data sharing and use agreement preclude sharing the raw Diversion Alert (arrest data). Data may be made available on request.

Open access This is an open access article distributed in accordance with the Creative Commons Attribution Non Commercial (CC BY-NC 4.0) license, which permits others to distribute, remix, adapt, build upon this work non-commercially, and license their derivative works on different terms, provided the original work is properly cited, appropriate credit is given, any changes made indicated, and the use is non-commercial. See: http://creativecommons.org/licenses/by-nc/4.0/.

\section{REFERENCES}

1. Ahmad FB, Rossen LM, Spencer MR, et al. Provisional drug overdose death counts. National Center for Health Statistics 2018 https://www.cdc.gov/nchs/nvss/vsrr/drug-overdose-data.htm

2. Piper BJ, Desrosiers CE, Fisher HC, et al. A new tool to tackle the opioid epidemic: description, utility, and results from the Maine Diversion Alert Program. Pharmacotherapy 2017;37:791-8. 
3. Martin SL, Desrosiers C. Diversion Alert: 1-year evaluation across northern New England, 2013-2014. Prev Chronic Dis 2016;13:E159.

4. Piper BJ, Desrosiers CE, Lipovsky JW, et al. Use and misuse of opioids in Maine: Results From pharmacists, the Prescription Monitoring, and the Diversion Alert Programs. J Stud Alcohol Drugs 2016;77:556-65.

5. Piper BJ, Shah DT, Simoyan OM, et al. Trends in medical use of opioids in the U.S., 2006-2016. Am J Prev Med 2018;54:652-60.

6. Piper BJ, Suarez MJ, Piserchio JP, et al. Illicit and prescription drug misuse as reported to the Maine Diversion Alert Program. Forensic Sci Int 2018;285:65-71.

7. Koechl B, Unger A, Fischer G. Age-related aspects of addiction. Gerontology 2012;58:540-4

8. Centers for Disease Control and Prevention. CDC Vital Signs: prescription painkiller overdoses: a growing epidemic, especially among women. 2013 www.cdc.gov/vitalsigns/prescriptionpainkillerov erdoses/index.html

9. Substance Abuse and Mental Health Services Administration (SAMHSA). Results from the 2013 National Survey on Drug Use and Health: Summary of National Findings. Rockville, MD: Substance Abuse and Mental Health Services Administration, 2014. HHS Publication No. (SMA) 14-4863. NSDUH Series H-48.

10. Rollason V, Vogt N. Reduction of polypharmacy in the elderly: a systematic review of the role of the pharmacist. Drugs Aging 2003:20:817-32.

11. Greene MS, Chambers RA. Pseudoaddiction: fact or fiction? an investigation of the medical literature. Curr Addict Rep 2015;2:310-7.

12. Culberson JW, Ziska M. Prescription drug misuse/abuse in the elderly. Geriatrics 2008;63:22-31.

13. McCall KL, et al. Controlled substance prescribing trends and physician and pharmacy utilization patterns: epidemiological analysis of the Maine Prescription Monitoring Program from 2006 to 2010. J. Substance Use 2013;18:467-75.

14. Manchikanti L, Sanapati J, Benyamin RM, et al. Reframing the prevention strategies of the opioid crisis: focusing on prescription opioids, fentanyl, and heroin epidemic. Pain Physician 2018;21:309-26.

15. Andrilla CHA, Moore TE, Patterson DG, et al. Geographic distribution of providers With a DEA waiver to prescribe buprenorphine for the treatment of Opioid Use Disorder: A 5-year update. J Rural Health 2019;35:108-12.

16. Sorg MH, Greenwald M. Patterns of drug-related mortality in Maine, 1997-2002. Maine Policy Review 2003;12:84-96.

17. Buchanich JM, Balmert LC, Williams KE, et al. The effect of incomplete death certificates on estimates of unintentional opioidrelated overdose deaths in the United States, 1999-2015. Public Health Rep 2018;133:423-31.

18. Seth P, Scholl L, Rudd RA, et al. Overdose deaths involving opioids, cocaine, and psychostimulants - United States, 2015-2016. MMWR Morb Mortal Wkly Rep 2018;67:349-58.

19. Lozier MJ, Boyd M, Stanley C, et al. Acetyl fentanyl, a novel fentanyl analog, causes 14 overdose deaths in Rhode Island, March-May 2013. J Med Toxicol 2015;11:208-17.

20. Pichini S, Solimini R, Berretta P, et al. Acute intoxications and fatalities from illicit fentanyl and analogues: An update. Ther Drug Monit 2018;40:38-51.

21. Avedschmidt S, Schmidt C, Isenschmid D, et al. Acetyl fentanyl: trends and concentrations in metro detroit. J Forensic Sci 2019:64:149-53.

22. O'Donnell J, Gladden RM, Mattson CL, et al. Notes from the field: overdose deaths with carfentanil and other fentanyl analogs detected - 10 states, July 2016-June 2017. MMWR Morb Mortal Wkly Rep 2018;67:767-8

23. Sorg MH. Expanded Maine drug death report for 2017. $2018 \mathrm{https}: / /$ mcspolicycenter.umaine.edu/wp-content/uploads/sites/122/2018/04/ Final-Annual-2017-Drug-Death-Report .pdf

24. Sorg MH, Greenwald M, Wren JA. Patterns of drug-induced mortality in Maine, 2015 update. Maine Policy Review 2016;25:34-46.

25. DEA. National Heroin Threat Assessment Summary. $2016 \mathrm{https} / /$ www.dea.gov/divisions/hq/2016/hq062716_attach.pdf

26. Guarino H, Mateu-Gelabert P, Teubl J, et al. Young adults' opioid use trajectories: From nonmedical prescription opioid use to heroin, drug injection, drug treatment and overdose. Addict Behav 2018;86:118-23.

27. Stanley TH. The fentanyl story. J Pain 2014;15:1215-26.

28. Kuczyńska K, Grzonkowski P, Kacprzak $Ł$, et al. Abuse of fentanyl: An emerging problem to face. Forensic Sci Int 2018;289:207-14.

29. Creppage KE, Yohannan J, Williams K, et al. The rapid escalation of fentanyl in illicit drug evidence in Allegheny County, Pennsylvania, 2010-2016. Public Health Rep 2018;133:142-6.
30. Mattick RP, Kimber J, Breen C, et al. Buprenorphine maintenance versus placebo or methadone maintenance for opioid dependence. Cochrane Database Syst Rev 2004;3:CD002207.

31. Comer SD, Collins ED. Self-administration of intravenous buprenorphine and the buprenorphine/naloxone combination by recently detoxified heroin abusers. J Pharmacol Exp Ther 2002;303:695-703

32. McPherson SM, Burduli E, Smith $\mathrm{CL}$, et al. A review of contingency management for the treatment of substance-use disorders: adaptation for underserved populations, use of experimental technologies, and personalized optimization strategies. Subst Abuse Rehabil 2018;9:43-57.

33. Wen H, Hockenberry JM, Borders TF, et al. Impact of Medicaid expansion on medicaid-covered utilization of buprenorphine for Opioid Use Disorder treatment. Med Care 2017;55:336-41.

34. Federal Bureau of Investigations. Uniform Crime Report 2012. 2014 https://www.fbi.gov/about-us/cjis/ucr/crime-in-the-u.s/2012/crimein-the-u.s.-2012/tables/33tabledatadecoverviewpdf

35. Gerdle B, Björk J, Cöster L, et al. Prevalence of widespread pain and associations with work status: a population study. $B M C$ Musculoskelet Disord 2008;9:102.

36. National Institute of Mental Health. Anxiety disorders. 2018 www. nimh.nih.gov/health/topics/anxiety-disorders/index.shtml

37. National Heart, Lung, and Blood Institute (NHLBI). Problem sleepiness in your patient. Bethesda, MD: National Institutes of Health, 1997. NIH Publication No. 97-4073.

38. Anthony JC, Warner LA, Kessler RC. Comparative epidemiology of dependence on tobacco, alcohol, controlled substances, and inhalants: basic findings from the National Comorbidity Survey. Exp Clin Psychopharmacol 1994;2:244-68.

39. Dluzen DE, Liu B. Gender differences in methamphetamine use and responses: a review. Gend Med 2008;5:24-35.

40. Lookatch SJ, Moore TM, Katz EC. Effects of gender and motivations on perceptions of nonmedical use of prescription stimulants. J Am Coll Health 2014;62:255-62.

41. Broséus J, Gentile N, Esseiva P. The cutting of cocaine and heroin: a critical review. Forensic Sci Int 2016;262:73-83.

42. Broséus J, Gentile N, Bonadio Pont F, et al. Qualitative, quantitative and temporal study of cutting agents for cocaine and heroin over 9 years. Forensic Sci Int 2015;257:307-13.

43. Ojha SP, Sigdel S, Meyer-Thompson HG, et al. 'South Asian cocktail'--the concurrent use of opioids, benzodiazepines and antihistamines among injecting drug users in Nepal and associations with HIV risk behaviour. Harm Reduct J 2014;11:17.

44. Mallick-Searle T, Snodgrass B, Brant JM. Postherpetic neuralgia: epidemiology, pathophysiology, and pain management pharmacology. J Multidiscip Healthc 2016;9:447-54.

45. Smith RV, Havens JR, Walsh SL. Gabapentin misuse, abuse and diversion: a systematic review. Addiction 2016;111:1160-74.

46. Stassinos GL, Klein-Schwartz W. Bupropion "abuse" reported to US Poison Centers. J Addict Med 2016;10:357-62.

47. Evoy KE, Morrison MD, Saklad SR. Abuse and misuse of pregabalin and gabapentin. Drugs 2017;77:403-26.

48. Oppek K, Koller G, Zwergal A, et al. Intravenous administration and abuse of bupropion: A case report and a review of the literature. $J$ Addict Med 2014;8:290-3.

49. Gulec N, Lahey J, Suozzi JC, et al. Basic and advanced ems providers are equally effective in naloxone administration for opioid overdose in northern New England. Prehosp Emerg Care 2018;22:163-9.

50. Vivolo-Kantor AM, Seth P, Gladden RM, et al. Vital Signs: Trends in emergency department visits for suspected opioid overdoses United States, July 2016-September 2017. MMWR Morb Mortal Wkly Rep 2018;67:279-85.

51. Higashikawa Y, Suzuki S. Studies on 1-(2-phenethyl)-4-(Npropionylanilino)piperidine (fentanyl) and its related compounds. VI. Structure-analgesic activity relationship for fentanyl, methylsubstituted fentanyls and other analogues. Forensic Toxicol 2008;26:1-5

52. Pubchem Open Chemistry database. Carfentanil. 2018 https:// pubchem.ncbi.nlm.nih.gov/compound/carfentanil\#section= Pharmacology-and-Biochemistry

53. Ricker NN. Only Walgreens selling Narcan in Bangor without a prescription. $2018 \mathrm{https} / / /$ bangordailynews.com/2017/07/ $21 /$ health/only-walgreens-selling-narcan-in-bangor-without-aprescription/

54. Haegerich TM, Paulozzi LJ, Manns BJ, et al. What we know, and don't know, about the impact of state policy and systems-level interventions on prescription drug overdose. Drug Alcohol Depend 2014:145:34-47. 
55. Delcher C, Wang Y, Young HW, et al. Trends in Florida's prescription drug monitoring program registration and utilization: implications for increasing voluntary use. J Opioid Manag 2017;13:283-9.

56. Sacco LN, Duff JH, Sarata AK. Prescription drug monitoring programs. Congressional Research Service:R42593.
57. Florence CS, Zhou C, Luo F, et al. The economic burden of prescription opioid overdose, abuse, and dependence in the United States, 2013. Med Care 2016;54:901-6. 